\title{
What Are Chinese Immigrant Parents' Concerns with Their Children's Education?
}

George Zhou

RCIS Working Paper No. 2013/4

September 2013

SERIES EDITOR

Harald Bauder

Ryerson Centre for Immigration \& Settlement Ryerson University Jorgenson Hall, 620 350 Victoria Street, Toronto, ON M5B2K3 http://www.ryerson.ca/rcis 
RCIS Working Paper

No. $2013 / 4$

\title{
What Are Chinese Immigrant Parents' Concerns with Their Children's Education?
}

\author{
George Zhou \\ University of Windsor
}

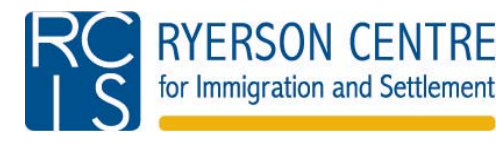

Series Editor: Harald Bauder

RCIS Working Papers present scholarly research of all disciplines on issues related to immigration and settlement. The purpose is to stimulate discussion and collect feedback. The views expressed by the author(s) do not necessarily reflect those of $\mathrm{RCIS}$. For a complete list of RCIS publications, visit www.ryerson.ca/rcis

ISSN: 1929-9915

This RCIS Working Paper was presented at the 2013 RCIS conference "Immigration and Settlement: Precarious Futures?" held at Ryerson University, May 15-17, 2013. This publication and the conference received funding from the Social Sciences and Humanities Research Council of Canada.

cc) (i) $\Theta$ Creative Commons Attribution-Noncommercial-No Derivative Works EY NO ND 2.5 Canada License 


\section{Abstract}

This study investigated teachers' experiences of communicating with Chinese immigrant parents. Twenty teachers were recruited for interviews from local schools that had a large enrollment of Chinese immigrant students.

Participating teachers reported that Chinese immigrant parents often expect high marks from their children and want to know their child's ranking in the class. These parents also place pressure on children to achieve parentallyestablished goals. Participating teachers view a well-rounded education as the purpose of schooling, rather than high marks. They were frustrated by parents' concern over children's class ranking, and the parental focus on children's perceived weaknesses. Teachers also reported that Chinese parents should ease the pressure they place on children, suggesting that parents should encourage children to participate in extra-curricular activities. They also suggested that Chinese parents should be more sensitive to their children's preferences.

Key words: Chinese immigrant parents, teacher-parent communication, culture, parental involvement

\section{Introduction}

Children education is by no means a sole task of teachers and schools. Parent involvement is significant. Effective home and school communication is crucial for creating shared goals between parents and teachers, avoiding misunderstanding, and guiding parents' involvement in activities at home. According to Eberly, Joshi, and Konzal (2007), children are raised within the overlap of micro- (within families and schools), meso- (the relationship between families and schools), and macro- (cultural notions of development) systems. Open communication between the meso-level links must be secured if children are to grow and learn (Epstein, 2001). Well-structured home-school communication "can impart information to help parents become more knowledgeable about children's learning activities, aware of their positive qualities and progress, and informed about how they, as parents, might help their child learn" (Ames et al., 1993, p.3). Epstein (1991) argues that healthy home and school communication should be frequent, bidirectional, and ongoing, establishing meaningful connections between teachers and parents. However, current research suggests that home-school communication happens infrequently in today's education settings, and the quality of that communication is unsatisfactory.

Communication between home and school becomes even harder for immigrant parents when extra barriers arise from cultural differences (Schmidt, 1994; Voltz, 1994). In recent years, there has been a dramatic increase in the number of immigrants from mainland China to Canada (Statistics Canada, 2008). Although a number of studies report on Chinese immigrant parents' involvement in their children's education, most focus solely on home-based activities ( $\mathrm{Li}, 2007$ ), with only a few exceptions that examine school-based involvement (Dyson, 2001; Zhong \& Zhou, 2011). Studies on Chinese immigrant families find that Chinese parents are often passive in 
initiating communication with school and teachers (Wang, 2008), and they are frequently dissatisfied with the effectiveness of programs designed to bridge home-school communication (Guo \& Mohan, 2008). Zhong and Zhou (2011) report that factors such as lack of English proficiency, commitments to timedemanding jobs, cultural differences, and unfamiliarity with the Canadian education system are creating barriers to Chinese immigrant parents' active school involvement. It is our belief that these factors influence Chinese parents' communication with school teachers as well.

The communication between Chinese parents and teachers is intercultural, impacted by "large and important cultural differences [that] create dissimilar interpretations and expectations about how to communicate competently" (Guo \& Mohan, 2008: 19). According to Spinthourakis, KaratziaStalioti, and Roussakis (2009: 268), "intercultural communication consists of the cognitive, affective, and behavioral ability of participants in the communication process." The cognitive aspect of intercultural communication refers to the concept of intercultural awareness, and the affective aspect is represented by the concept of intercultural sensitivity. People who have developed intercultural sensitivity should actively desire to motivate themselves to understand, appreciate, and accept differences from other cultures. The behavioral aspect of intercultural competence is represented by the concept of multifaceted intercultural readiness that prepares individuals to act accordingly. Along those lines, Spitzberg and Cupach (1984) argued that there were three necessary and interdependent ingredients of communication competence: knowledge, motivation, and behavior.

This study investigated teachers' impressions of Chinese immigrant parents' concerns with their children's education. The accuracy of teachers' understandings represents the effectiveness of intercultural communication with Chinese immigrant parents, influencing their communication practices with this group of parents.

\section{Methods}

Over the last few years, we conducted studies investigating Chinese immigrant parents' communication with school teachers in Windsor, Ontario. Since 1991, Chinese immigrants have formed the largest population arriving in the Windsor area from any individual region (Statistics Canada, 2008). This makes the city of Windsor an ideal location for research involving Chinese immigrants. Using surveys and interviews, our 2011 study investigated the communication experiences of both teachers and Chinese immigrant parents. First, quantitative data was collected in order to gauge Chinese immigrant parents' experience, satisfaction, challenges, and expectations of communicating with school teachers. Then, semi-structured interviews were conducted with Chinese immigrant parents and teachers. The findings from that survey have been published elsewhere (Jiang, Zhou, Zhang, Beckford, \& Zhong, 2011). This paper turns to the findings from teacher interviews.

Semi-structured interviews were conducted with teacher participants to collect information about their communication experiences with Chinese immigrant parents. Permission to conduct the in-school study was sought from principals of schools with a large enrollment of Chinese immigrant 
students. Teacher participants were then recruited through school principals who also volunteered to distribute interview invitations to their teachers. Given the ease of access and communication with teacher participants, principals also helped researchers set up interview schedules. We recruited 20 teachers from one secondary and two elementary schools, and our final sample included seven secondary school teachers (two males and five females) and thirteen elementary school teachers (all females). The majority of teacher participants had taught in the local education system for many years, with an average of 15 years. On average, each interview lasted 45 minutes. All teacher interviews were conducted in English and audio was recorded with permission from participants.

\section{Findings}

\section{Methods of Communication}

All of the teacher participants conveyed that they opened the door to Chinese immigrant parents and were willing to communicate with them. Teachers initiate meetings with parents to review students' study progress, health problems, behavioral problems, and so forth. The teacher-parent interview remains the primary occasion for teacher-parent communication, though teachers also employ other means of communication with parents. These include class newsletters, phone calls, notes written in students' agendas, casual after-school conversations, blogs, and websites. Among these other, more informal modes of communication, the student agenda book is used widely for daily communication. Teachers write notes to inform parents about what is going on in school or request meetings. Teachers also ask parents to sign agendas every day to make sure parents received the information. Many teachers feel that written notes are better than phone calls due to language difficulty. Participant 8, an elementary teacher, found that "with Chinese parents... it's better to send a note, because I think the phone call, there's that they don't understand, and you can't do gestures on the phone either."

Although written notes are frequently used in daily communication between teachers and parents, many participants preferred face-to-face communication with parents. Participant 4, an elementary teacher, suggested that "everybody prefers face-to-face conversation... I think a face-to-face conversation is always better most of the time." Furthermore, some teachers believed the brevity of written communication could cause misunderstanding. In this regard, Participant 6 prefers "one-on-one" meetings, as this "gets the message across. Sometimes with a written note, you can misinterpret the message."

\section{Chinese Parents' Main Concerns}

Teacher participants reported that Chinese immigrant parents frequently ask questions about their children's academic progress, marks, class ranking, extra work, and peer issues. All of the teachers felt strongly that Chinese immigrant parents place emphasis on or overemphasize academic 
achievements and ranking in class or among peers, but pay less attention to questions about how their child is interacting with other students. Participant 13, an elementary teacher, found that Chinese parents tend to ask "How are they [their children] doing? Are they doing their work in class? And often times they ask how they are doing compared to the other students in the class." She further commented that:

Mostly the concerns were the progress of their children academically. I find that the Chinese immigrant parents are concerned with academics, not so much the social or the other aspects of school, but their main focus was the progress and the academics.

Participant 7 spoke of a similar focus on academics:

Usually the academics. Usually focusing on math or the languages, sometimes science, but mostly with math, and how to improve their student to make them get to that level four. If they're at level four, how to continue to get them to an even higher level. So, always striving to do their best in academics. They often want extra work to be sent home to continue to reinforce the skills they're learning at school.

Participant 14, a secondary school teacher teaching Gifted Grade Ten, Academic Grade Ten, and University-level Grade Twelve students, compared Chinese parents and Canadian parents. She noted that while Chinese parents stress the marks themselves, Canadian parents wished to know the reasons for the marks. In terms of parents' concerns, she illustrated:

Obviously over the course of teaching, I'm generalizing here, but marks are always very important in general, with all students, Canadian or Chinese. With the Chinese immigrant parents I think there's even a greater stress on "What can my son/daughter do to get a better mark? What extra work can be done?" And that's not something the Canadian parents always ask. And again, I'm generalizing, because that's not always the case. But there's a higher rate of Chinese parents that say "What's the mark, how can it be better, what can they do?" Whereas, Canadian parents say "What's their mark? What's the problem? And why is it so low?" It's basically the same question, they want to find out how to raise the mark, but the Canadian question would be "Why is it so low?" and the Chinese question would be "What can we do to make it higher?" They don't want to know why; they want to know what to do to push it higher. They'll often ask those questions for extra work. 


\section{High Expectations for Academics}

Many of our participants observed that high expectations for academic success on the part of Chinese immigrant parents were expressed during teacher-parent interviews and other meetings. Participant 4, an elementary school teacher, expressed that "the only thing that I think that is much more prominent in the Chinese families is the interest in the academic aspect of their child." Participant 2, also an elementary school teacher, was surprised when parents came to her asking how to improve their children's marks from "A" to "A+", since typically:

...their students are doing well, and their parents will ask me, "Well how can I improve? My child has an A, and I want an A+" and that's sort of something I find surprising. It didn't happen this year because, as I said, this is a progress report, and we didn't give grades we just give "progressing well" or "very well". And again, I did have one parent say, "How can my child get 'very well' in everything." But again, I did explain that I hardly gave hardly any "very wells", I felt for me that was just the beginning so we're progressing "well". "Very well" would be sort of something later on, at the end of the year. But that was my personal philosophy. If you keep on doing well all year, then "very well" would be the outcome at the end of the year.

Though it is an uncommon phenomenon, one of our participants does talk about "Tiger-mom"-type parents, who ask for a high mark for their child and try to influence the grade given to their child by teachers. This behavior really challenges the normal school education and teachers' evaluation.

I think one of the things I would say right off the bat is, and again I don't want to generalize, because a lot of the Chinese immigrant parents are great, but l've had a few every year that can be very spirited in their attempts to talk to the teacher, so sometimes they'll show up in the middle of the day to talk to you, without any appointment, and say "I want my son to get a 90, so can you just give him a 90 now, and even though he has an 83 and the 90 will happen." Or "If my student can't get into university with this 90 average, we can't get his scholarship, and then I'll have to sell my house." So if you don't give the 90, they'll be out of a house. So there's some really intense pressure from the "Tiger-mom" type parent, which is the rarity, but it's there, to influence the grade. And I wouldn't necessarily give advice about what to do in those situations, but I would inform certain teachers, like "I've taught that student and their mom is very intense and she might put pressure on you, so be ready because that may happen." Because a lot of new teachers can be easier to manipulate, and they can get pushed around a little bit, but just say, "No, that's the mark and I can't change it. I can help your son/daughter to improve, but I can't change the mark." So that would be something I would talk about. There's a level of interest 
and intensity in some Chinese parents, that [which] is beyond the normal sort of interest that Canadian parents would have. (Participant 14 , secondary teacher)

Participating teachers expressed that they understood Chinese parental expectations but felt these parents pushed their children in academic performance while ignoring the pressure and learning difficulties their children might be experiencing. Participant 6 (elementary) spoke about one such case:

I think [the student's mom is] very stubborn, because having him in French school, when he's learning English... he doesn't speak English very well and he's now having to learn French, and on top of that he has so many difficulties that other students don't have. If you don't even talk about the language problem, he has other difficulties...I know in kindergarten they [teachers] were trying to convince her to put him in an English school, and she insisted he stay in the French school.

This parent insisted that her child be placed in French school because she had high expectations of him and wanted him to receive the best education. Participant 6 commented further, saying:

I feel that she just wants him to have all the advantages in life. And that's why parents put their children in French. Especially in Canada, we're a bilingual country; they want their children to have both languages. My parents did that for me, I understand, it makes sense. If I have children I will put them in French. But for this particular situation, it may not be a good situation; it may not be the best thing for him. That's why I think she's very stubborn, she's pushing, and telling us all he needs is time.

Participant 18 (secondary) narrated her difficult communications with one set of Chinese parents regarding their child. She attempted to convince them to stop placing extra pressure on him, as he was a hard worker but not a top student:

I know that the student is a hard worker. I can see by the previous teacher's comment, but their marks are perhaps just standard or, you know, average. Nothing is wrong with that. We are not all the top level thinkers, and society doesn't need all people to be at the top of the brain, so I see this and I sense the pressure on the child because you need to perform better. You need to perform better, so that's where I make every effort to talk to the parent and try to make them realize your child is working hard, that should be the focus, congratulate them because they are working hard. They only got seventy percent but 
that's the process that counts. They are hard workers. That's a great quality for your child. How, you know, to try to ease the pressure that I really feel a lot of times the parent is putting on the child and no matter how hard the child worked, they are not going to achieve ninety percent and there is nothing wrong with them. So that is one of the main issues that I've encountered and it's a real problem that I've had with parents.

Participant 17 (secondary) also felt that Chinese students were pushed harshly by their parents, even though they were self-conscious and had a good academic record.

Most of the Chinese kids are very self-conscious kids, but I do have some Chinese kids with poor math skills so they do struggle in the physics course. Most of the parents want to know how to improve from an $85 \%$ to a $95 \%$. That's what they want to know. $85 \%$ is not enough, how do I go from and $85 \%$ to a $95 \%$ ? And when they see the test paper, if the kid does one single mistake, the parents become so upset. It's just one test, in the long run the test is going to be worth one or two percent of the mark. If the kid is not working hard, if the kid is not listening, if the kid is not even making an attempt that's when you should be concerned. When the kids are responsible by themselves, I think that's what you should appreciate.

She voiced the opinion that parents should relax about marks and give their children some opportunity to make choices.

I think two days before the report card, in my grade 11 class everybody was crying. Because some of them said, "Having an 82 is terrible." That's what they said, 82 in physics. I said, "Excuse me? 82 in physics is such an awesome mark, what are you talking about?" And they say, "No Miss, can you please come and tell my parents, they won't understand this." So they are all terrified of their parents saying, "You have to get that 95, you have to go to a US school, you have to go to Ivy League, you need to write SATs." The stress on the kids is enormous. If you just remove that, I think kids will do very well by themselves. Give them some freedom of making a choice, and I'm going to sit here and watch you do it. If I think you are doing it wrong, I'm going to jump in and say, "That's not going to work." I think many kids are afraid, scared.

Many new immigrants choose to enroll their children in the best academic schools rather than institutions where their children can receive better English as a second language (ESL) support. An ESL specialist reported that Chinese parents send their children to the best academic schools without considering 
whether their children's language proficiency is sufficient for a more intensive level of study:

It's patience that I'm trying to help you understand that an ESL program would benefit your student, your son or daughter. And they don't want that. It's like a war, [and] they don't want to accept defeat. And it's not defeat...they feel they're doing the best for their child, not knowing the system that's in Canada. Because the system in China is completely different, this is what I'm trying to voice: that the Ministry of Education has guidelines. So, be it at xx [a famous academic school], be it at xx [a school with an ESL program], be it at any other school, they have to obey those guidelines. (Participant 16, secondary school ESL specialist)

\section{Class ranking}

Although not every Chinese immigrant parent emphasized class ranking and comparison with other students, some of them were very keen to know where their child ranked and how their child compared with the rest of the class. This made some teacher participants uncomfortable. Participant 2 (elementary) gave an example of what she had encountered:

I have thirty students. They wanted to know where their child ranked. That made me uncomfortable because I didn't feel that there's just one way to look at one's ability; you may be really good in one dimension thinking in your head with math concepts, but not good at another concept. So I didn't want parents to say, "Oh you're not number one, we got to keep going." I got that feeling a little bit, so I said "You know your child is doing very well, and keep doing what you're doing, and if I see that there's something not going well, then I will communicate with you". They need to trust that I will be in touch with them if there's a problem, and I ask them to do the same for me.

Participant 2 was unwilling to share Chinese immigrant parents' concerns with class rankings because of her different perspective on evaluation. In teacherparent meetings, she attempted to share her perspective with those parents:

Well, I'll say I'm not prepared to give you that, and I'm certainly not looking at it that way. I'm not looking at who is my number $1,2,3,4 \ldots$. I'm looking at the students as what their strengths are and what they can do with that, and let's work with that, and the areas that need the extra help, we'll support that. 
Responding to our question, "How and what do you feel when parents ask how their kid is doing compared with the class?", Participant 19 (secondary) did not understand why Chinese parents are keen to know other students' marks and felt that they were demanding a lot from their children.

Why do you need to know that? What difference does it make where everyone falls? We're here to talk about your son/daughter. The competition doesn't mean anything to how he's doing. It won't make him any better." But they are very interested in those numbers and it really does come down to numbers, and that is very frustrating because we teach people, and we want parents to be interested in their children's being. Not as just an output on a report card. And sometimes it's very frustrating, they're very dismissive of their children, "Why didn't you do more?" We hear what the students do in terms of the hours of homework they have, the violin practice, or the piano practice, and all the things that they do. There's no time for them to do more. But yet, there is an insistence that they have not done enough. And so they turn to us, and say, "You have to tell us what more they're doing." Often these students have marks over A, marks that are over 80, and they come to us and say, "It's not enough, it must be better."

Participant 20 (secondary) also expressed disapproval of Chinese immigrant parents' over-passionate attachment to ranking.

"Does my child rank in the top of the class? How far? How many children are above my child?" So they want to know what the rankings are. I think if we post it on the board, they would be very happy. And I've had parents actually take my computer and insist on seeing that information, and I've had to take my computer back and say, "That's private confidential information and you can't have that." They want printouts of other student marks, all kinds of things that they will ask. I generally try to direct the conversation back to the child, and focus on the child. I find it very helpful when the student is there, because then you can talk to the student and not just address the parent.

Participant 14 (secondary) also mentioned a similar experience with some parents who insisted on inquiring after other students' marks regardless of privacy issues.

I've had only Chinese parents asking me the marks of the other students, "I want to see how this person or this person is doing." Or "Just let me see your sheet," because they know the other 5 students they want to see, not their son/daughter, but someone else's marks. And technically you shouldn't do that - it's a privacy issue. But 
sometimes, I've had my computer up with my marks on it, and they'll just grab it and turn it around, and if I'm not ready to grab it, they'll just do that... And I've never felt that those parents are being rude on purpose, they just really want to know.

Participant 3 (elementary) found that Chinese parents usually want to know, "How is the student doing in relation to the whole class? So, were they within the average, above average, or below? Or can they have more activities to do at home, any homework?" She usually provided parents with their children's standing relevant to the class average since this information was already on the report card. However, she also tried to discourage Chinese immigrant parents from comparing their children with others in terms of ranking, arguing:

...there's more than one dimension to a student, not just the academics. So it's very important for the student to be a whole person. So some students may struggle academically, but may be very helpful, may be very resourceful, and a good team player. So those are qualities that are important too. So, for the parent whose child is a high achiever, academically, but is not strong socially, I encourage the parents to expose the child to extra-curricular activities so they have more opportunities to socialize. One example would be, in the past I've had many students who are the only child [in their family], so one boy or one girl, and in many cases they are very lonely, because they don't have siblings to play with. And after school they have piano or dance and they are always alone. They have voiced that to me. So that is what I encourage the parents... So if they are academic achievers, yes that's good, but it shouldn't be only academics, it should be the whole person.

\section{Academic-Focused vs. Well Rounded}

Many Chinese immigrant parents overemphasize academic study and underestimate the importance of having their children participate in extracurricular activities. Some of them even hope that the teacher can persuade their child to stop pursuing extra-curricular activities. From teachers' perspectives, this view is narrow-minded and can hinder children's wellrounded development and the formation of personality. Participant 1 (elementary) gave us a concrete example where she spoke with a concerned father in order to convince him that his son should continue to participate in sports.

Yes, and I actually have him [the student] this year and I haven't met with the dad yet so I don't know. We haven't had any communication so far, obviously I think it's good because he hasn't come in. But I know two years ago when I was coaching the track team, this dad was very 
concerned about his child being on the track team, he came to talk to me and said he wasn't sure if he should spend his time doing that. We talked about the advantages of being healthy and he's very talented, and why wouldn't you let him shine in different areas. He's a very smart young man and achieves excellent grades, so he does that already, you want him to be more complete. So I think it's worked out well because that was two years ago, and last year he was on the track team, and this year he's doing sports. I think his dad is seeing the reason of that, but he questioned it at the beginning. We were concerned because he's a good athlete too, so you want the children to grow in all aspects of their life.

Likewise, Participant 9 (elementary) indicated the importance of physical activity, but was aware of a lack of encouragement in that direction in the Chinese community.

I think also what is important is physical activity, and putting them on a sports team and having that collaboration with other kids their own age. So I think that is something that is lacking a bit, in the Chinese community, or with my Chinese students. ...I think what they should incorporate also is bringing in athletics, having them let out in a different way, communicate with other kids of even different cultures is what I think would help them to be more involved in the community in that way, rather than always academically.

Participant 4 (elementary) also took students' social ability into consideration.

I will suggest activities, such as doing things at parks and recreation... There's lots of parks and recreation here in the city. It's amazing, they have swim programs and gymnastics and all those kinds of things that teach children how to become more social and I do try to promote that.

Participant 3 (elementary) thought:

Cultural differences are difficult to explain because different people think different things, but as a teacher we observe how students interact at school and if we see that something is not right, we like to help. If we see that this child is more involved in playing in the neighborhood or having activities after school that involves a group, he will make friends more easily. That's what I'm trying to say, making friends, associating with other people. 
However, this teacher's perspective on the importance of social engagement was not shared by the father of one of their students, who wanted his child to go to Harvard University. Participant 3 communicated with this parent several times in order to ensure that the student could participate in sports.

The boy wanted to play on the school volleyball team, and when they were doing tryouts he didn't sign up, and I said, "Why didn't you try out?" He said, "Madame, I can't because I have to study." I said, "I don't think so, you have to try out for that team." He said, "Madame my dad won't allow me." And I said, "I'll call your father." I explained to him that it was very important for that boy to play in the school team because he was making friends, he wanted to play, and it's a good skill. After a couple of conversations, he said, "Well if he passes the tryouts then I'll allow him to play." He did let his son play, but I had to interfere. It was a good thing. He was happy outside on the playground. He was playing with the team players. (Participant 3, elementary)

In this case, it seemed that the father's intense interest in academic achievements had greatly impacted the student, who felt he was superior to his peers because of his focus on academics.

I expressed to him [the father] that it would be a good idea for him [the student] to play volleyball but also to, at home, have all of those activities but include some play time with friends. That's when he said, "No, he needs to work hard because he needs to go to university." The boy already knew that he had to work hard, and so what comes with this is that the child can think that he is superior to everyone else. This creates a problem because he thinks, "I am better than you" with the rest of the class. That was coming across and I sat down and talked to him, and he said, "Because Madame, all they do is play they don't study after school." I said, "No that's not the way it is. Maybe they have different activities after school that we don't know. Maybe their parents can't afford to pay for Kumon or violin, that doesn't mean that they aren't as good as you are." Those are the things that if the child is not exposed to other children they can't understand how people are different. Being different doesn't mean you're bad, you're worse than me. No. Being different just means you're different, different ways of doing the same thing. (Participant 3, elementary)

When being asked about the difficulty she had in communicating with Chinese immigrant parents, Participant 12 (elementary) told us that one student's parents did not want their child to do anything concerning the arts, even though the student had an excellent academic record. 
I'm thinking about one case in particular where a student was an exceptional student in every area, scoring extremely high, but there was never any happy medium. It was never good enough even when you're scoring 100 and doing more than you can. She really liked to paint. She made me that painting over there and I think that was the last painting she ever did because her parents didn't want her to paint anymore. It was one of my most memorable and very unfortunate interviews because she wrote beautiful stories, they didn't want her writing stories- they wanted her writing non-fiction pieces. She was very good at writing non-fiction pieces. She was very well rounded, she knew about current events, she made connections, she loved science, but her passion was to write. She would write beautiful stories, beautiful poetry, and she loved to paint. But, her parents wanted her to do more stuff. But she did more stuff, but I found it was never good enough for the parents. They ended up moving to Troy, Michigan, so I haven't heard from them since. But that was a concern, they wanted more, but they weren't sure what more was because she was shining in all areas. I think it was coming to the point where the student was starting to rebel against the parents. You can never say a child is perfect, [but] she was perfect, and it was just not good enough. I think it was just backfiring on the parents.

The thing was that they didn't want her to focus on any sort of the arts. She was a masterful pianist, beautiful writer, beautiful artist, as well as scoring top marks in math and science. It was a very frustrating interview because I wasn't understanding where they wanted this child to go. I think they were frustrated with their daughter. I don't know what was going on, but the daughter was a teenager, so starting to rebel or perhaps talk back to her parents. She was frustrated too. Her parents were frustrated, and she was frustrated.

\section{External Desire vs. Intrinsic Motivation}

Many of our teacher participants observed that Chinese immigrant parents place significant pressure on their children. Though some of them understand it as coming from a Chinese culture of hard work, discipline, and excellence, others disagree with this parenting model. As Participant 4 (elementary) figured out, "I feel that, especially within the Asian community, there is a lot of pressure that is put on." She went on to say:

Because I've been in the culture, [and] I've lived there, I understand what it means to want to succeed. It's funny that you asked because the other day I asked my students, "What kind of extra work do you do at home? If your family makes you go to Sylvan, or to have a tutor, or you go to a math program after school? " And it was funny, the majority of my Chinese students had... and I wrote it down, and they told me everything that they do after school. All the extra things their parents make them do after school. So I understand the culture, I do. 
Participant 20 (secondary) disagreed with this parenting style dependent on externally-imposed, high expectations. Instead, she stressed the intrinsic motivation of students. As she explained:

I think sometimes in those conversations the student is silent, and the parent wants to talk to us, so I always try to be aware to direct that conversation back to the student. I don't ignore their concerns, and I understand where they come from, but ultimately this is the system in which their student is operating, so I have to address the student needs not an external desire, not an extrinsic motivation, because if that student is not internally motivated they're not going to do better anyway. So sometimes those students are very discouraged when the parents are focused so much on the ranking and the mark, and what I have to be sure to do is make sure they're intrinsically motivated, not just motivated by "Here's the mark you have to attain."

In response to parental demands for more extra homework, Participant 2 (elementary) felt uncomfortable and insisted that students' own willingness should be considered.

...I'm not comfortable doing that, because first of all, I'm concerned about what the child would perceive, he'd say "Why am I getting more work, the others aren't, how come these students are not doing anything, and I have to do more?" There would not be a balance for the students themselves in the class. The other thing I'll often do is to tell their parents, if their child wants to do more, and they want to show it to me they can, but I will not grade it, I will look at it and discuss it with them....and reward them from the conversation so that they know where they stand.

She also felt that it was difficult to communicate with Chinese parents when she thought they pushed their children too hard.

I want them to realize that it's not the same as the other students. But at the same time I want them to feel that it's ok to do that, that's how it works for their family, they want their child to excel, and it works in their house. Again, finding the right words to sort of not make them feel uncomfortable, but also at the same time, not make them feel they need to pressure their child. Sometimes I'm a little afraid of that. (Participant 2, elementary) 


\section{Conclusion and Discussion}

Interviews demonstrated a strong perception among participating teachers that Chinese immigrant parents emphasize academics. Many teacher participants reported that Chinese parents often focus their dialogue with teachers at the teacher-parent conferences on their children's marks. This forms a discrepancy with our findings from the parental survey. When speaking of the content of communications, the parental survey revealed that Chinese parents spoke about a wider range of topics, not focusing only on their children's academic progress. Although academic issues were indeed mentioned by the greatest portion of participants (75\%), the content of communications covered other aspects of their children's education as well. For example, about $68 \%$ and $50 \%$ of participating parents also discussed their children's behavioral issues and social relationships respectively. It was also found that parents tended to communicate more when there was a need to talk about children's behavioral issues (Jiang et al., 2012).

The discrepancy regarding perceived content of teacher-parent communication between teachers and what was actually revealed in the survey of Chinese parents may require further research for a more complete explanation. One possible explanation is that Chinese parents' concern with academic standing overwhelmed teachers' memories of their communication experiences, given parents' lesser concern over non-academic matters.

Interviews revealed differing educational values between Chinese immigrant parents and school teachers. Educated in a highly competitive system, Chinese immigrant parents often wanted to know their children's ranking in their class. In China, teachers post students' marks publicly so that each student knows where he or she stands in relation to their peers. Parents ask their children about their exam ranking before other details. Teachers provide this information to parents without hesitation. Therefore, class rank becomes the most significant indicator for parents of their children's performance in school. Parents are comforted by a high class ranking for their children, and they feel pressure in cases of low rankings. However, Canadian school teachers do not share this desire for evaluating children's performance through class ranking, considering this practice a violation of student privacy. Canadian teachers do not believe that parents have a right to know how other children perform on an exam. They do not really consider class ranking to be part of the norm of evaluating students in Canada since they are more concerned with student progress and differentiated instruction.

Chinese culture sees education as a tool for social mobility (Zhong \& Zhou, 2011). The significance of good marks has been reinforced through the Civic Service Exam in old China, which recruited national and local civil servants based on exam scores, as well as the test-based school and college admission system established in the past few decades, which regulates progression from lower to higher levels of education. While Chinese parents realize that a well-rounded education is more important than a sole focus on academics (Jiang et al. 2012), cultural inertia, to borrow a concept from physics, still influences thinking in many aspects of their life, including involvement in their children's education. If their children score $85 \%$ grades, they always wanted to push for $95 \%$, or even higher. Parents wanted teachers to identify their children's weaknesses, so that they could help to push their 
children to another level of excellence. In contrast, Canadian teachers view well-rounded education as the purpose of schooling. They suggested that Chinese parents should ease the pressure they put on their children and encourage their children to engage in extra-curricular activities. They tended to emphasize the positive sides of students and did not talk much about students' weaknesses at teacher-parent meetings.

Chinese immigrant parents tend to establish goals for their children. They want their children to go to Ivy League or other key universities. With these goals in mind, they push their children to do things that will enable them to achieve these goals. Ironically, although almost all Chinese parents send their children to music or drawing classes at early ages, they do not want their children to pursue such majors at university because they believe these majors will not ensure good jobs after graduation. Many of them want their children to major in areas like medical science or business, which will secure them good jobs. Children are considered successful only when they enroll in such universities or majors. Chinese immigrant parents prefer to identify children's weaknesses and gaps relative to these long-term goals, engaging with their education by forcing him or her to make improvements. In contrast to this final product-orientated parenting style, Canadian teachers suggest that Chinese parents should be alert to their children's preferences and attentive to their children's daily education, adopting a process-oriented view of education.

\section{Acknowledgement}

This study was funded by a CERIS grant, which is a sub-SSHRC grant. The author owes great thanks to Dr. Zuochen Zhang for his contribution to data collection and doctoral candidate Jie Zheng for her assistance in data analysis. The author also wants to thank the school teachers who participated in the study.

\section{References}

Ames, C., Khoju, M., \& Watkins, T. 1993. Parent Involvement: The Relationship between School-to-Home Communication and Parents' Perceptions and Beliefs. Report No. 15: Publications, Center on Families, Communities, Schools \& Children's Learning. Baltimore, Maryland: Johns Hopkins University.

Dyson, L. L. 2001. "Home-School Communication and Expectation of Recent Chinese Immigrants." Canadian Journal of Education 26(4): 455-476.

Eberly, J. L., Joshi, A., \& Konzal, J. 2007. "Communicating with Families Across Cultures: An Investigation of Teacher Perceptions and Practices." The School Community Journal 17(2): 7-26. 
Epstein, J. L. (Ed.). 2001. School, Family, and Community Partnerships: Preparing Educators and Improving Schools. Boulder, CO: Westview Press.

Epstein, J. L., \& Dauber, S. L. 1991. "School programs and teacher practices of parent involvement in inner-city elementary and middle schools." The Elementary School Journal 91(3): 289-305.

Guo, Y., \& Mohan, B. 2008. "ESL Parents and Teachers: Toward Dialogue?" Language and Education 22(1): 17-33.

Jiang, F., Zhou, G., Zhang, Z., Beckford, C., \& Zhong, L. 2012. Chinese Immigrant Parents Communication with School Teachers." Canadian and International Education 41(1): 59-80.

Li, G. 2007. "Home Environment and Second-Language Acquisition: The Importance of Family Capital." British Journal of Sociology of Education 28(3): 285-299.

Schmidt, P. R. 1994. "Home/School connection: The vital factor in bilingual ethnic-minority literacy learning." Paper presented at the annual meeting of the National Reading Conference, San Diego. December.

Spinthourakis, J. A., Karatzia-Stavlioti, E., \& Roussakis, Y. 2009. "Pre-service Teacher Intercultural Sensitivity Assessment as a Basis for Addressing Multiculturalism." Intercultural Education 20(3): 267-276.

Spitzberg, B., \& Cupach, W. 1984. Interpersonal Communication Competence. Beverly Hills, CA: Sage.

Statistics Canada. 2008. Canada's Ethnocultural Mosaic, 2006 Census. Retrieved from http://publications.gc.ca/collections/collection 2010/statcan/CS97-5622006-1-eng.pdf

Voltz, D. L. 1994. "Developing Collaborative Parent-Teacher Relationships with Culturally Diverse Parents." Intervention in School \& Clinic 29(5): 288-291.

Wang, D. 2008. "Family-School Relationships as Social Capital: Chinese Parents in the United States." The School Community Journal 18(2): 119-146.

Zhong, L., \& Zhou, G. 2011. "Chinese Immigrant Parents' Schoollnvolvement: High Interest but Low Action." The Brock Education Journal 20(2): 4-21 